\title{
Oyster-Derived Tyr-Ala (YA) Peptide Prevents Lipopolysaccharide/D-Galactosamine-Induced Acute Liver Failure by Suppressing Inflammatory, Apoptotic, Ferroptotic, and Pyroptotic Signals
}

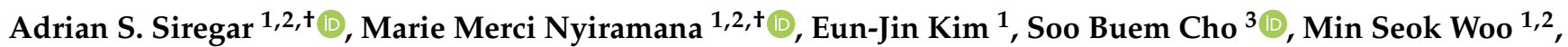 \\ Dong Kun Lee ${ }^{1,2} \mathbb{D}^{D}$, Seong-Geun Hong ${ }^{1}$, Jaehee Han ${ }^{1}$, Sang Soo Kang 2,4 (D), Deok Ryong Kim ${ }^{2,5}$ (D), \\ Yeung Joon Choi ${ }^{6}\left(\mathbb{D}\right.$ and Dawon Kang ${ }^{1,2, *(\mathbb{D})}$
}

check for updates

Citation: Siregar, A.S.; Nyiramana, M.M.; Kim, E.-J.; Cho, S.B.; Woo, M.S.; Lee, D.K.; Hong, S.-G.; Han, J.; Kang, S.S.; Kim, D.R.; et al. Oyster-Derived Tyr-Ala (YA) Peptide Prevents Lipopolysaccharide/D-GalactosamineInduced Acute Liver Failure by Suppressing Inflammatory, Apoptotic, Ferroptotic, and Pyroptotic Signals. Mar. Drugs 2021, 19, 614. https:// doi.org/10.3390/md19110614

Academic Editors: Donatella Degl'Innocenti and Marzia Vasarri

Received: 6 October 2021

Accepted: 26 October 2021

Published: 28 October 2021

Publisher's Note: MDPI stays neutral with regard to jurisdictional claims in published maps and institutional affiliations.

Copyright: (c) 2021 by the authors. Licensee MDPI, Basel, Switzerland. This article is an open access article distributed under the terms and conditions of the Creative Commons Attribution (CC BY) license (https:/ / creativecommons.org/licenses/by/ $4.0 /)$.
1 Department of Physiology and Institute of Health Sciences, College of Medicine, Gyeongsang National University, Jinju 52727, Korea; adriansiregar46@gmail.com (A.S.S.); mariemerci1994@naver.com (M.M.N.); eunjin1981@hanmail.net (E.-J.K.); whitewms@naver.com (M.S.W.); dklee@gnu.ac.kr (D.K.L.); hong149@gnu.ac.kr (S.-G.H.); jheehan@gnu.ac.kr (J.H.)

2 Department of Convergence Medical Science, Gyeongsang National University, Jinju 52727, Korea; kangss@gnu.ac.kr (S.S.K.); drkim@gnu.ac.kr (D.R.K.)

3 Department of Radiology, Ewha Womans University Seoul Hospital, Seoul 07804, Korea; kingnose80@gmail.com

4 Department of Anatomy and Institute of Health Sciences, College of Medicine, Gyeongsang National University, Jinju 52727, Korea

5 Department of Biochemistry, College of Medicine, Gyeongsang National University, Jinju 52727, Korea

6 Ocean-Pep, Jinju Bioindustry Foundation, Jinju 52839, Korea; yjchoi@gnu.ac.kr

* Correspondence: dawon@gnu.ac.kr

+ These authors contributed equally to this work.

Abstract: Models created by the intraperitoneal injection of lipopolysaccharide (LPS) and D-galactosamine (D-GalN) have been widely used to study the pathogenesis of human acute liver failure (ALF) and drug development. Our previous study reported that oyster (Crassostrea gigas) hydrolysate $(\mathrm{OH})$ had a hepatoprotective effect in LPS/D-GalN-injected mice. This study was performed to identify the hepatoprotective effect of the tyrosine-alanine (YA) peptide, the main component of $\mathrm{OH}$, in a LPS/D-GalN-injected ALF mice model. We analyzed the effect of YA on previously known mechanisms of hepatocellular injury in the model. LPS/D-GalN-injected mice showed inflammatory, apoptotic, ferroptotic, and pyroptotic liver injury. The pre-administration of YA ( $10 \mathrm{mg} / \mathrm{kg}$ or $50 \mathrm{mg} / \mathrm{kg}$ ) significantly reduced the liver damage factors. The hepatoprotective effect of YA was higher in the $50 \mathrm{mg} / \mathrm{kg}$ YA pre-administered group than in the $10 \mathrm{mg} / \mathrm{kg}$ YA pre-administered group. These results showed that YA had a hepatoprotective effect by reducing inflammation, apoptosis, ferroptosis, and pyroptosis in the LPS/D-GalN-injected ALF mouse model. We suggest that YA can be used as a functional peptide for the prevention of acute liver injury.

Keywords: acute liver injury; apoptosis; ferroptosis; inflammation; oyster; peptide; pyroptosis

\section{Introduction}

Acute liver failure (ALF) is the most common life-threatening disease in adults without pre-existing liver disease, and it mainly occurs in the 30s [1]. There are many causes of ALF that include hepatitis, acetaminophen overdose, toxins, autoimmune diseases, Wilson's disease, and unknown factors. Herbal supplements cannot be free from triggers of ALF [2]. Since there are few effective treatments for ALF other than liver transplantation, studies to find strategies for the treatment and prevention of ALF using experimental animal models are continuously being performed. In the early stages of ALF, the incidence of bacterial infection is high [3,4], which might aggravate the clinical condition and prognosis [5]. An 
uncontrolled inflammatory response not only impairs the liver's defenses but also causes massive cell death of hepatocytes, leading to acute liver damage and ultimately severe ALF $[1,6]$.

A model made by the intraperitoneal injection of lipopolysaccharide (LPS) and Dgalactosamine (D-GalN) has been widely used to study the pathogenesis of human ALF and drug development [7] because it shows clinically similar symptoms to ALF [8]. LPS, the major pathogenic component of Gram-negative bacteria, induces the secretion of large amounts of pro-inflammatory cytokines and ultimately causes liver injury [9-11]. D-GalN, a selective hepatotoxin, induces depletion of the intracellular uridine moiety, which in turn disrupts the hepatocyte RNA metabolism and results in liver injury [12,13]. D-GalN increases the sensitiveness of LPS and causes hepatotoxicity within a few hours. The LPS/D-GalN model shows typical hepatocellular death manifested by necrosis, apoptosis, autophagy, and inflammatory responses [14-16]. Although many studies have not been conducted, recent studies reported that cell death mechanisms by ferroptosis, pyroptosis, and necroptosis are involved in liver injury in the LPS/D-GalN model [17-19]. Substances that regulate signals related to the hepatocyte death mechanism are expected to be helpful in the prevention and treatment of LPS/D-GalN-induced liver injury.

Conventional drugs used to treat liver diseases, such as corticosteroids, antiviral drugs, and immunosuppressants, can cause serious adverse effects and even liver damage with long-term use [20]. A common strategy for preventing liver damage includes using substances with antioxidant and anti-inflammatory activity [21]. Natural products with antioxidant and anti-inflammatory activities, such as silymarin, were developed as hepatoprotectants [22]. However, since silymarin interacts with CYP2C9 inhibitors, caution is required when taking drugs related to CYP2C9 inhibitors [23]. It is necessary to broaden the choice of natural medicines suitable for individual patients by developing natural hepatoprotectants and therapeutic agents with fewer side effects than silymarin.

In our previous studies, oyster-derived hydrolysate $(\mathrm{OH})$ showed hepatoprotective effects in a single ethanol binge model and a LPS/D-GalN-induced liver injury model [24,25]. In particular, the Tyrosine-Alanine (YA) peptide, the main component of $\mathrm{OH}$, enhanced the ethanol metabolism and protected the liver from ethanol-induced toxicity [25]. YA has antioxidant and anti-inflammatory activities. Bioactive peptides affect various biological functions, and peptides have been used as therapeutic agents for various diseases for a long time [26]. Arg-Gly-Asp (RGD) peptide attenuates LPS-induced pulmonary inflammation [27] and hepatic fibrosis [28]. Currently, there are few studies on the hepatoprotective mechanism of YA against the LPS/D-GalN-induced liver injury model. Since the YA peptide is a food-derived substance, the preventive effect was first investigated before the therapeutic effect. This study was performed to determine the hepatoprotective effect of the YA peptide in the LPS/D-GalN-induced ALF model. We also compared the effects of two different concentrations of YA (10 and $50 \mathrm{mg} / \mathrm{kg})$.

\section{Results}

\subsection{Generation of Acute Liver Failure (ALF) Mouse Model}

The method to produce an ALF mouse model and the experimental procedure to confirm the prophylactic effect of YA are summarized in Figure 1A. The ALF model was generated by the intraperitoneal injection of LPS $(1 \mu \mathrm{g} / \mathrm{kg})$ and D-galactosamine $(400 \mathrm{mg} / \mathrm{kg})$, and the mice were sacrificed $6 \mathrm{~h}$ after the LPS/D-GalN injection. The five experimental groups were divided into the vehicle, LPS/D-GalN, YA (10 or $50 \mathrm{mg} / \mathrm{kg}$ ) + LPS/D-GalN, and silymarin (25 mg/kg) + LPS/D-GalN groups (each group with 10 mice). YA and silymarin were pre-administrated orally for 10 days. Saline was pre-administered instead of YA in the vehicle and LPS/D-GalN groups. Body weight was measured at the beginning and end of the experiment, and liver weight was measured immediately after sacrificing the mice. There was no significant change in body and liver weights among the experimental groups. 


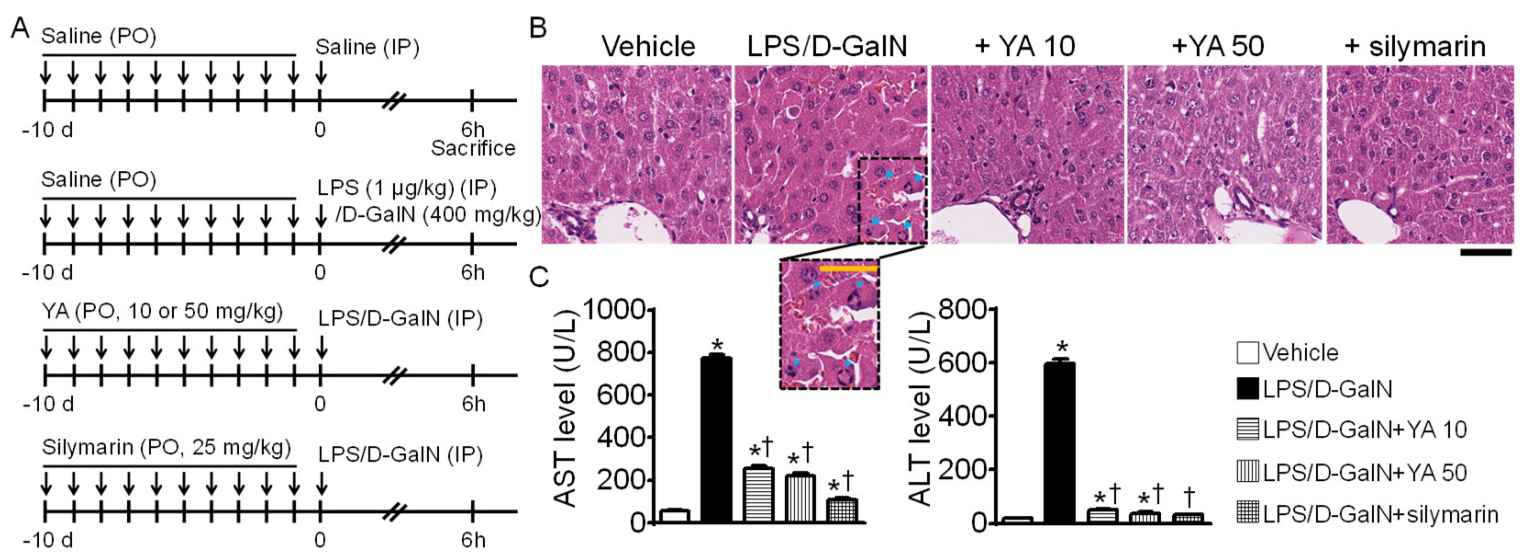

Figure 1. LPS/D-GalN-induced acute liver failure (ALF) mouse model. (A) Experimental design to determine the protective effect of YA in the ALF mouse model. Saline, YA, or silymarin was pre-administered daily for ten days by oral gavage before intraperitoneal injection of LPS/D-GalN. (B) LPS/D-GalN-induced pathological alterations in liver tissue attenuated by YA. The morphological changes were identified by H\&E staining. The dotted rectangle representing the hemorrhage area is expanded to show. Blue arrowheads indicate nuclear fragmentation. Scale bar, $100 \mu \mathrm{m}$. (C) Effect of YA pre-administration on plasma ALT and AST levels in the LPS/D-GalN group. Data are shown as the mean \pm SD ( $\mathrm{n}=10$ in each group). ${ }^{*} p<0.05$ compared to vehicle group. ${ }^{\dagger} p<0.05$ compared to the LPS/D-GalN group.

The morphological changes of the liver observed in the experimental groups were evaluated by hematoxylin and eosin (H\&E) staining. The LPS/D-GalN group showed a remarkable increase in hemorrhage and nuclear fragmentation (dotted rectangle, Figure 1B). The morphological features of cell damage were reduced in the YA+LPS/D-GalN and silymarin+LPS/D-GalN groups. Comparing the effects of two different concentrations of YA, the cell damage was decreased more in the $50 \mathrm{mg} / \mathrm{kg}$ YA pre-administered group than in the $10 \mathrm{mg} / \mathrm{kg}$ YA pre-administered group. Silymarin $(25 \mathrm{mg} / \mathrm{kg})$, a positive control showing hepatoprotective effects, reduced the LPS/D-GalN-induced morphological features of cell damage ( $n=3$, Figure 1B). Alanine aminotransferase (ALT) and aspartate aminotransferase (AST) levels in the LPS/D-GalN group were significantly increased compared to the vehicle group $(p<0.05)$. In contrast, they were significantly decreased in the YA and silymarin pre-administered groups (Figure $1 C, n=10, p<0.05$ ).

\subsection{YA Pre-Administration Attenuated Inflammatory Signals in ALF Model}

YA significantly decreased the activity of the biosynthesis enzymes cyclooxygenase-2 (COX-2) and 5-lipoxygenase (5-LO), which are involved in the inflammatory process. The effect was dose-dependent ( $\mathrm{n}=4, p<0.05$, Figure $2 \mathrm{~A}$ ). The nuclear factor kappa-lightchain-enhancer of activated B cells (NF- $\mathrm{kB}$ ), a key transcription factor for pro-inflammatory gene induction, was significantly activated in liver tissues obtained from the LPS/D-GalN groups compared to the vehicle group (Figure $2 \mathrm{~B}, \mathrm{n}=4, p<0.05$ ). The NF- $\kappa \mathrm{B}$ activation was significantly decreased in the $50 \mathrm{mg} / \mathrm{kg}$ YA + LPS/D-GalN and silymarin + LPS/D-GalN groups (Figure 2B, $\mathrm{n}=4, p<0.05$ ). In the NF- $\mathrm{kB}$ activity, the $10 \mathrm{mg} / \mathrm{kg}$ YA + LPS/D-GalN group showed no significant difference from the vehicle and LPS/D-GalN groups.

Mitogen-activated protein kinase (MAPK) activation is related to LPS-induced inflammation [29]. Extracellular signal-regulated kinase 1/2 (ERK), c-Jun N-terminal kinases (JNK), and p38 MAPKs were significantly activated in the LPS/D-GalN group compared to the vehicle group (Figure $2 \mathrm{~B}, p<0.05, \mathrm{n}=4$ ). ERK and JNK activation was significantly decreased in the $50 \mathrm{mg} / \mathrm{kg}$ YA + LPS/D-GalN group $(p<0.05)$, whereas p38 activation was significantly reduced in the $10 \mathrm{mg} / \mathrm{kg}$ and $50 \mathrm{mg} / \mathrm{kg}$ YA and silymarin pre-administered groups (Figure $2 \mathrm{C}, \mathrm{n}=4, p<0.05$ ), indicating that $\mathrm{YA}$ and silymarin may act through different mechanisms. Activation of NF- $\mathrm{KB}$ and MAPK is associated with the secretion of pro-inflammatory cytokines such as interleukin (IL)- $1 \beta$, IL-6, and tumor necrosis factor (TNF)- $\alpha[30,31]$. High concentrations of IL- $1 \beta$, IL-6, and TNF- $\alpha$ in the LPS/D-GalN 
group were significantly reduced in the YA + LPS/D-GalN group (Figure $2 \mathrm{D}, \mathrm{n}=4$, $p<0.05)$. The secretion of IL- $1 \beta$, IL-6, and TNF- $\alpha$ was more decreased in the $50 \mathrm{mg} / \mathrm{kg}$ YA pre-administered group than in the $10 \mathrm{mg} / \mathrm{kg}$ YA pre-administered group. The mRNA expression levels of IL-1 $\beta$, IL-6, and TNF- $\alpha$ were also decreased in the YA + LPS/D-GalN groups (Figure 2D).
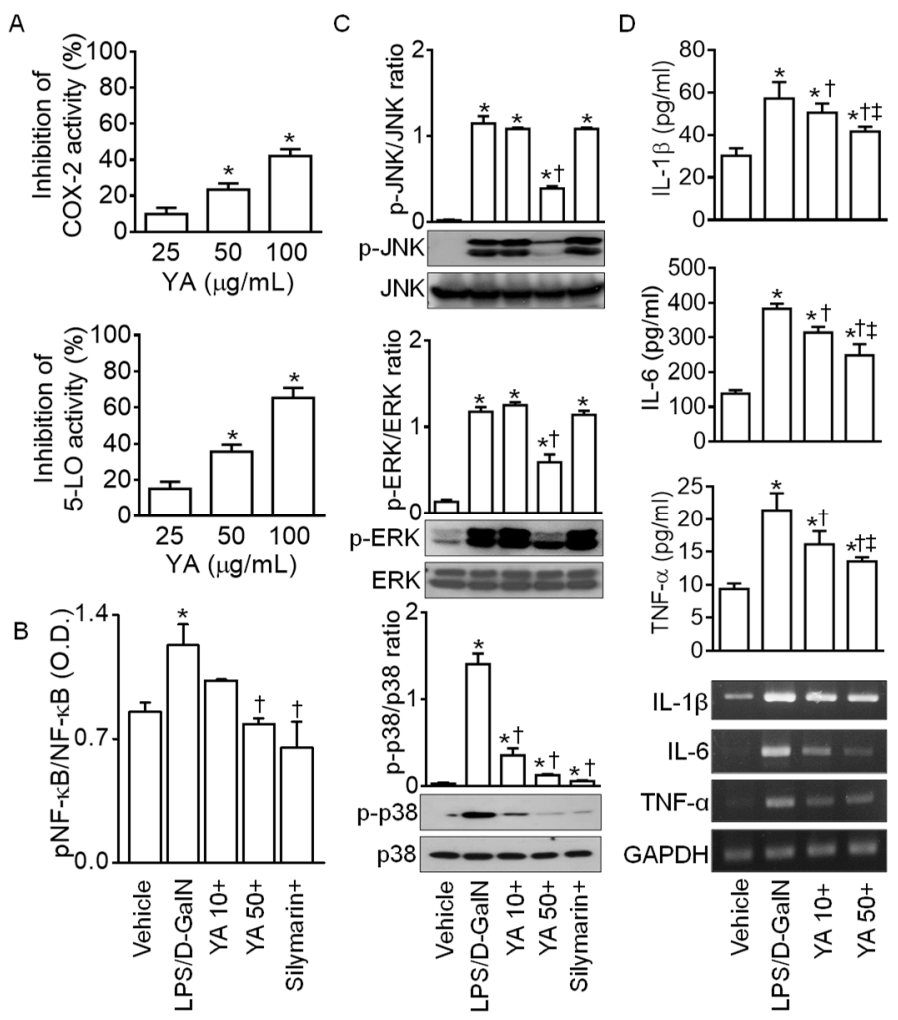

Figure 2. Anti-inflammatory effect of YA in LPS/D-GalN-induced ALF model. (A) Inhibition of cyclooxygenase-2 (COX-2) and 5-lipoxygenase (5-LO) activity by YA. ${ }^{*} p<0.05$ compared to $25 \mu \mathrm{g} / \mathrm{mL}$ YA. (B) Changes in NF- $\kappa$ B activation. The NF- $\kappa$ B activity was measured using a phospho-NF- $\mathrm{B}$ p65 (S536) ELISA kit. (C) Suppression of MAPK activation by YA. (D) Decrease in pro-inflammatory cytokines (IL-1 $\beta$, IL-6, and TNF- $\alpha$ ) by YA. Data are shown as the mean \pm SD $(n=4$ in each group). ${ }^{*} p<0.05$ compared to vehicle group. ${ }^{\dagger} p<0.05$ compared to the LPS/D-GalN group. ${ }^{\ddagger} p<0.05$ compared to YA $(10 \mathrm{mg} / \mathrm{kg})+$ LPS/D-GalN group. The plus (+) sign, such as in YA10+, YA50+, and silymarin+, represents a combination of LPS/D-GalN and each substance.

\subsection{YA Pre-Administration Attenuated Apoptotic Signals in ALF Model}

Apoptotic signals were analyzed in liver tissues obtained from the LPS/D-GalNinjected mice. The number of apoptotic cells exhibiting green fluorescence was increased in the LPS/D-GalN group. In contrast, the number of these cells was decreased in the YA and silymarin pre-administered groups, according to terminal deoxynucleotidyl transferase dUTP nick end labeling (TUNEL) staining, a method detecting DNA fragmentation of apoptotic cells (Figure 3A). In the LPS/D-GalN group, the B-cell lymphoma protein 2 (Bcl-2)-associated X (Bax)/Bcl2 ratio was increased; poly ADP-ribose polymerase (PARP) and caspase 3 (Cas 3 ) were cleaved, and mitochondrial cytochrome $C$ was secreted into the cytoplasm. In comparison to the LPS/D-GalN group, the apoptotic signals were significantly reduced in the YA and silymarin pre-administered groups (Figure $3 \mathrm{~B}, p<0.05$, $\mathrm{n}=4$ ). The inhibitory effect on LPS/D-GalN-induced apoptotic signals was higher in the $50 \mathrm{mg} / \mathrm{kg}$ YA pre-administration group than in the $10 \mathrm{mg} / \mathrm{kg}$ YA pre-administration group. 
A
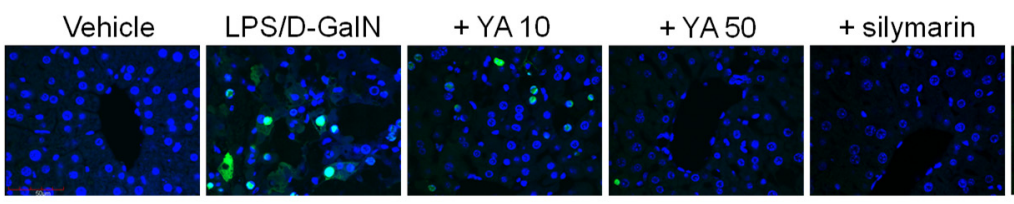
PC

B
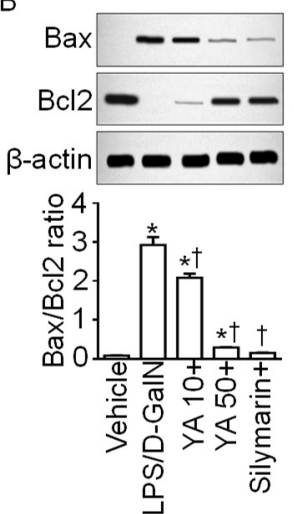
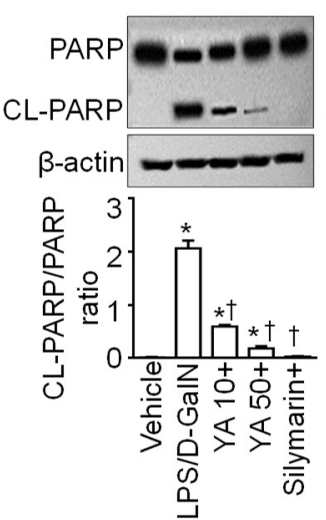
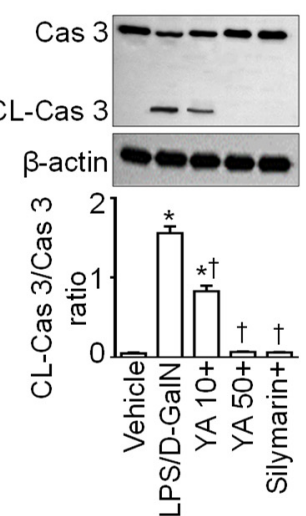

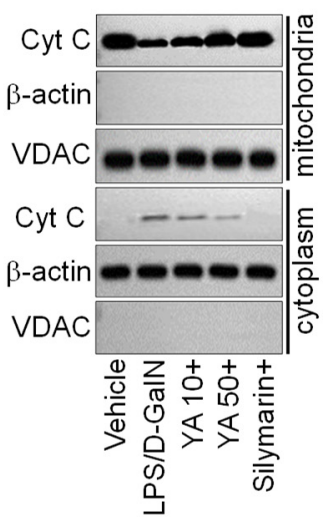

Figure 3. Anti-apoptotic effect of YA on liver tissues obtained from LPS/D-GalN-injected mice. (A) TUNEL staining. Representative fluorescence images of hepatocyte apoptosis in LPS/D-GalN group. Positive control (PC) treated with DNase I is displayed as a comparison. The cells showing green fluorescence in the nucleus are apoptotic. Scale bar, $200 \mu \mathrm{m}$. (B) Western blotting assay for detection of apoptotic signals. Pro-apoptotic Bax and anti-apoptotic Bcl2 expression levels, cleaved (CL) PARP and caspase 3 (Cas 3), and translocation of cytochrome C (Cyt C) into cytoplasm were analyzed. Data are shown as the mean $\pm S D$ ( $n=4$ in each group). ${ }^{*} p<0.05$ compared to vehicle group. ${ }^{+} p<0.05$ compared to the LPS/D-GalN group. The plus sign (+) represents a combination of LPS/D-GalN and each substance.

2.4. YA Pre-Administration Attenuated Endoplasmic Reticulum (ER) Stress and Ferroptosis and Pyroptosis Signals in ALF Model

ER stress is related to various cell death mechanisms. ER stress-related proteins such as GRP78, PERK, eIF2 $\alpha$, ATF4, ATF6, and CHOP were upregulated in the LPS/D-GalN group (Figure 4A). The upregulated ER stress markers were markedly decreased in the YA and silymarin pre-administered groups. SLC7A11, GPx4, and HO-1 suppression are linked to ferroptosis induction, while 4-HNE upregulation is related to lipid peroxidation during this process. SLC7A11, GPx4, and HO-1 protein expression levels were decreased in the LPS/D-GalN group, while the 4-HNE protein expression level was increased. The changes in the ferroptosis markers were significantly restored in the YA and silymarin pre-administered groups (Figure $4 \mathrm{~B}, p<0.05, \mathrm{n}=3$ ).

Pyroptotic cell death was detected in the LPS/D-GalN group. The caspase-1 was cleaved, and the gasdermin D (GSDMD) was upregulated. In addition, the carboxyterminal gasdermin-C domain cleaved in gasdermin D (CL-C-terminal GSDMD) was detected in the LPS/D-GalN group (Figure 4C). IL-1 $\beta$ was highly secreted in the LPS/DGalN group (see Figure 2D). The pyroptotic signals were significantly reduced in the YA+LPS/D-GalN and silymarin+LPS/D-GalN groups (Figure 4C, $p<0.05, \mathrm{n}=3$ ).

The mechanisms involved in liver injury in LPS/D-GalN-injected mice are summarized in Figure 5. 

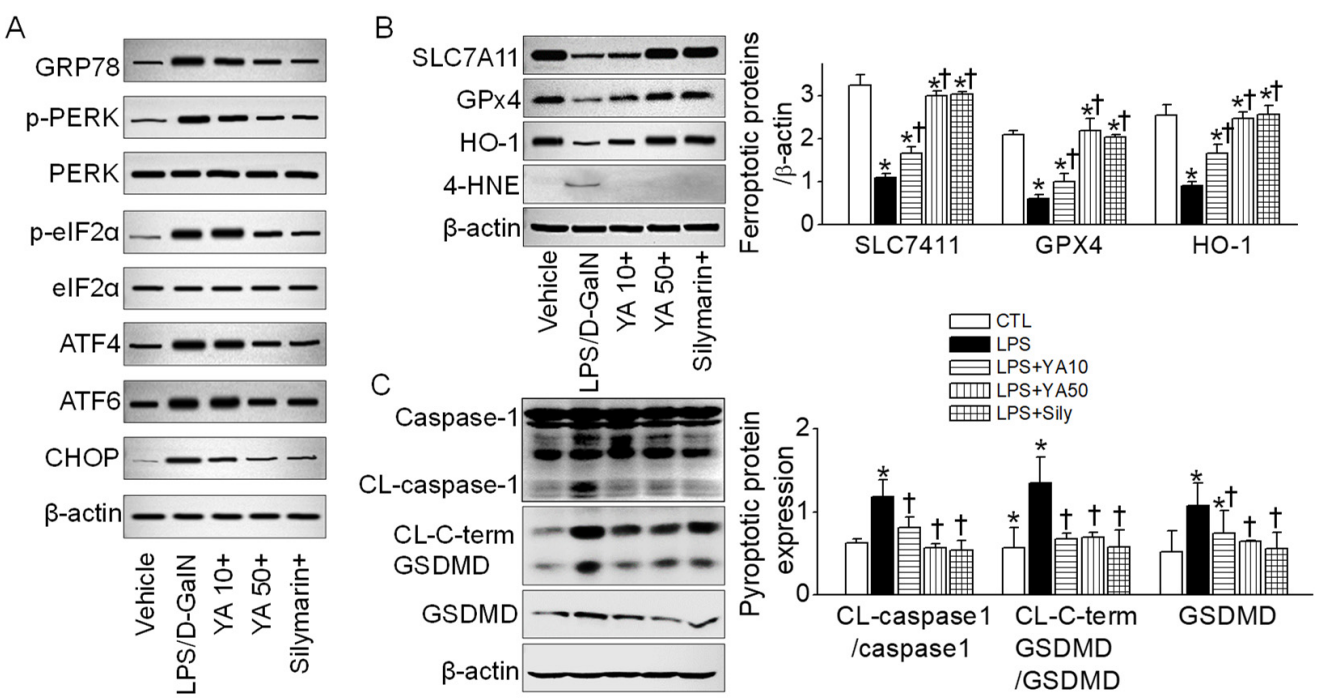

Figure 4. Ferroptotic and pyroptotic signals decreased by YA pre-administration. (A) Changes in ER stress markers. (B) Changes in ferroptosis markers. (C) Changes in pyroptosis markers. Data were shown as the mean $\pm \mathrm{SD}$ ( $\mathrm{n}=3$ in each group). $(\mathbf{B}, \mathrm{C})$ share a label representing each experimental group. ${ }^{*} p<0.05$ compared to vehicle group. ${ }^{+} p<0.05$ compared to the LPS/D-GalN group. The plus sign (+) means the combination of LPS/D-GalN and each substance.

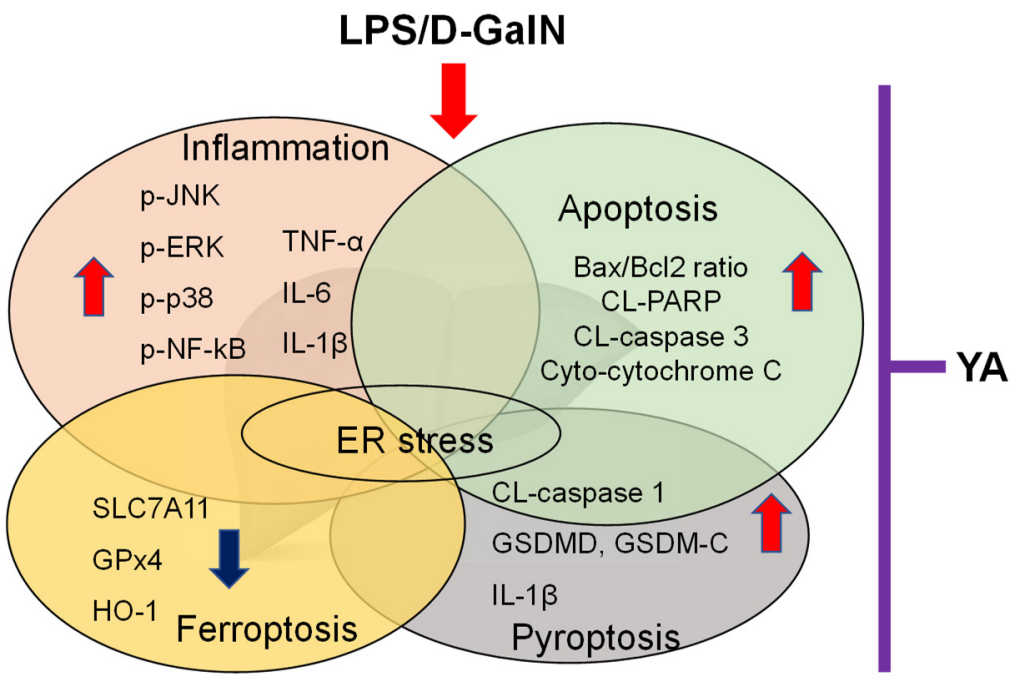

Figure 5. Various mechanisms were observed in liver tissues obtained from the LPS/D-GalN-induced ALF model. Pre-administration of YA reduced LPS/D-GalN-induced liver damage factors. The mechanisms are interconnected and can exacerbate liver damage.

\section{Discussion}

This study analyzed the effect of YA on previously known mechanisms of hepatocellular damage in a mouse model capable of mimicking ALF symptoms. LPS/D-GalN-injected mice used as an ALF model in this study are also referred to as models for fulminant liver failure (FLF), acute liver injury (ALI), and acute hepatitis. Previous studies reported that liver damage in LPS/D-GalN-injected mouse models is induced by multiple complex mechanisms, such as inflammation, apoptosis, necrosis, autophagy, pyroptosis, necroptosis, and ferroptosis [14-19]. However, most previous studies using LPS/D-GalN-injected mouse models analyzed one or two of the mechanisms mentioned above and reported that many hepatoprotectants proposed in those studies modulate the analyzed mechanisms. Since various factors and mechanisms cause ALF, substances that can control several mechanisms at once will be more helpful in treating ALF. Many hepatoprotective natural 
substances are more likely to exert their effects by regulating multiple mechanisms rather than specifically regulating a single mechanism. However, due to the lack of research, only some mechanisms of action of these substances are known. Even if the effects of these substances are excellent, it is challenging to develop new drugs or healthy functional foods if the mechanism of action is not sufficiently analyzed.

Here, we introduce a YA peptide that regulates many pathological mechanisms occurring in the LPS/D-GalN-induced ALF model. YA reduced inflammation, apoptosis, ER stress, ferroptosis, and pyroptosis in a LPS/D-GalN-injected mouse model, eventually reducing liver injury. Dipeptide YA used in this study has not been studied as much as other peptides. The mechanism of LPS/D-GalN-induced liver injury is also associated with increased autophagy [16]. However, in our study, autophagy-related signals did not show consistent results, so autophagy was excluded from the hepatoprotective mechanism of YA. Necrotic events were confirmed by H\&E staining. Hepatocyte swelling along with shrinkage of the nucleus shown in the LPS/D-GalN-induced ALF model was reduced in the YA pre-administered group. Receptor-interacting protein kinase (RIPK) 1 and RIPK3, necroptosis markers, expression levels were also checked in the liver tissues obtained from the LPS/D-GalN-induced ALF model. There were no significant differences between the vehicle group and the LPS/D-GalN group. As a result, autophagy and necroptosis were excluded from YA-regulated mechanisms.

YA exerts an anti-inflammatory effect by reducing MAPK/NF- $\mathrm{kB}$ activity. Apoptosis plays a role in normal liver development. However, the over-activation of apoptosis may lead to hepatocellular damage [32,33]. YA exerts anti-apoptotic effects by decreasing the $\mathrm{Bax} / \mathrm{Bcl} 2$ ratio, PARP and caspase 3 cleavages, and cytochrome $\mathrm{C}$ translocation from the mitochondria to the cytoplasm. ER stress plays a role during LPS/D-GalN-induced apoptosis in the ALF model [34-36]. YA decreased most of ER stress protein expression. ER stress is related to apoptosis, inflammation, and pyroptosis [37,38]. Ferroptosis agents cause ER stress responses, which play an essential role in the cross-talk between ferroptosis and other types of cell death [39]. ER stress appears to mediate many kinds of cell death. Dysregulation of ferroptosis has also been associated with various liver diseases [40]. Ferroptosis occurs mainly due to downregulated system $x_{c}$ activity, inhibited glutathione peroxidase 4 (GPX4), and increased lipid ROS [41]. Functional subunit solute carrier family member 11 of system $\mathrm{x}_{\mathrm{c}}$ (SLC7A11), GPx4, and HO-1 protein expression are reduced in the LPS/D-GalNinduced liver injury model $[19,42]$. YA pre-administration reversed ferroptotic signals in the LPS/D-GalN-induced ALF model. Apoptosis, necroptosis, and pyroptosis can be switched by some molecules. GSDMD is a pore-forming protein that promotes pyroptosis and the release of pro-inflammatory cytokines [43]. GSDMD-mediated hepatocyte pyroptosis extends the inflammatory response to ALF by upregulating monocyte chemotactic protein $1 / C C$ chemokine receptor-2 to recruit macrophages [17,18]. YA pre-administration also decreased the upregulation of GSDMD, caspase 1 activation, C-terminal of GSDMD cleavage in the LPS/D-GalN induced ALF model. These signals are intricately intertwined in the ALF model and will act in complex ways. In addition, the analyzed mechanism may not be perfect. Other mechanisms will work. YA regulates various mechanisms, which can occur in the LPS/D-GalN-induced ALF model. Involvement in multiple mechanisms can be either an advantage or a disadvantage. The advantage is that it can be effective because it can block numerous pathways that can act as mechanisms of liver damage in the ALF model at once. The disadvantage is that since it blocks several pathways, the probability of side effects can be high, and YA may not work specifically for the ALF model. However, in terms of side effects, since YA is a peptide derived from natural products, it is considered that the possibility of side effects is low.

YA was used as a standard material for $\mathrm{OH}$. Although several peptides have been suggested as standard materials in the $\mathrm{OH}, \mathrm{YA}$ has advantages over other peptides. YA is readily available to be used because YA is synthesized and sold by several companies, including Sigma-Aldrich (\#T5128). Short peptides produced from proteins that have biological activity beyond their nutritional value are known as bioactive peptides. To achieve 
their "bioactive" roles, these peptides must be released by proteolysis (in vivo digestion, in vitro enzymatic hydrolysis, or bacterial fermentation) [44]. YA was released from oysters by enzymatic hydrolysis. Our previous studies demonstrated that $\mathrm{OH}$ produced by in vitro enzymatic hydrolysis of oysters contained various bioactive peptides such as TAY, VK, KY, FYN, and YA and displayed antihypertensive, anti-inflammatory, antidiabetic, antioxidative, and hepatoprotective effects in in vitro and in vivo tests [24,25,45-47]. YA can be a bioactive peptide.

In the case of peptides, when administered orally, they are broken down into amino acids in the gastrointestinal tract, which may weaken their effectiveness. When comparing the effects of oral and intraperitoneal administrations in a preliminary study, the YA effect was slightly higher when injected intraperitoneally, indicating that the peptide may be digested into amino acids without being wholly absorbed when YA was administered orally. However, it is thought that this disadvantage can be overcome by intramuscular, subcutaneous, or intravenous injection. If YA is catabolized, tyrosine and alanine will be produced. Tyrosine and alanine are non-essential amino acids. Alanine is the most common amino acid catabolized by the liver in mammals, and it contributes the most to the gluconeogenesis of the 15 glucogenic amino acids [48,49]. To clear the $\mathrm{N}$ metabolites generated by amino acid catabolism, peripheral tissues such as skeletal muscle produce alanine and glutamine as nitrogen carriers in the blood, which are then taken up by the liver and gut and safely disposed of ureagenesis, resulting in glucose production from alanine [48,49]. Furthermore, the ALT expressed in the liver is responsible for the alanine-pyruvate interconversion [50]. When hepatocytes are damaged, ALT is released into the bloodstream, increasing serum ALT activity [51]. In an ALF rat model treated with D-GalN, alanine administration was found to lower plasma levels of ALT and total bilirubin dramatically [52]. In a $\mathrm{CCl}_{4}$-induced hepatocyte necrotic rat model, alanine administration was shown to reduce the ALT rise and histological liver damage [53]. In addition, alanine treatment dramatically reduced lactate dehydrogenase levels in D-GalNtreated rat hepatocytes [53]. When dietary tyrosine levels are low, the liver can produce tyrosine by hydroxylating phenylalanine. Tyrosine can become an essential amino acid in conditions where the liver fails. Tyrosine shortage can cause net protein catabolism and muscle wasting, so it is important to get enough [54]. Furthermore, tyrosine that is overused is oxidized. Tyrosine is a ketogenic and glucogenic amino acid. Both glucose and fatty acids can be produced by tyrosine [54]. Blood tyrosine levels are supposed to rise as a result of all-cause liver disease [55]. However, the exact mechanism is not known, and there is little evidence that tyrosine has a direct influence on liver disease. The YA concentration in the gastrointestinal system did not vary significantly in the simulated digestion experiment, suggesting that YA can be absorbed into the blood without significant loss [45].

In addition, when comparing the hepatoprotective effect of YA between the group pre-administered with YA once a day for 10 days (10 days YA group) and the group preadministered with YA once a day (1 day YA group), the hepatoprotective effect of YA was slightly lower in the 1 day YA group than the 10 day YA group, with a reduction in liver damage. At 10 and $50 \mathrm{mg} / \mathrm{kg}$ concentrations of $Y A$, both concentrations effectively reduced liver damage in the LPS/D-GalN-induced ALF model, except for effects on ERK and JNK activation. The hepatoprotective effect was higher in the $50 \mathrm{mg} / \mathrm{kg}$ YA pre-administered group than in the $10 \mathrm{mg} / \mathrm{kg}$ YA pre-administered group. In addition, significant activation of ERK and JNK in the $50 \mathrm{mg} / \mathrm{kg}$ YA pre-administered group could act as a signaling pathway distinct from the silymarin pre-administered group. A single ethanol binge model with $50 \mathrm{mg} / \mathrm{kg}$ YA demonstrated a hepatoprotective effect [25]. Therefore, we compared the effect of low-dose $(10 \mathrm{mg} / \mathrm{kg})$ and high-dose $(50 \mathrm{mg} / \mathrm{kg})$ YA in the LPS/D-GalNinduced ALF model. It can become a more effective functional food and is more likely to be used as a pharmaceutical if it has an effect at a low concentration. Although less effective than $50 \mathrm{mg} / \mathrm{kg}$ YA, $10 \mathrm{mg} / \mathrm{kg}$ YA had a hepatoprotective effect, suggesting that it could be developed as a medication. YA did not cause hepatotoxicity at $50 \mathrm{mg} / \mathrm{kg}$, and it may affect other mechanisms that were not fully explored in this study. 
Food-derived bioactive peptides and peptide-rich protein hydrolysates could provide a safe alternative to synthetic pharmaceuticals for the prevention and treatment of acute and chronic diseases with fewer side effects. The positive effect of YA was confirmed in the acute inflammation models, but its effect should also be analyzed in the chronic models. The substances that modulate multiple mechanisms may be effective because they can control complex mechanisms that can coexist in a single disease. However, it will be necessary to investigate continuously the side effects of the substance on normal tissues. Our findings suggest that YA can be a hepatoprotectant in acute liver injury, such as ALF, FLF, and acute hepatitis as a bioactive peptide.

\section{Materials and Methods}

\subsection{Preparation of $Y$ A Peptide}

Crassostrea gigas specimens (length, $5.8 \pm 0.4 \mathrm{~cm}$; height, $3.2 \pm 0.4 \mathrm{~cm}$; body weight (BW), $9.8 \pm 2.1 \mathrm{~g}$ ) were harvested from a fish farm in Tongyeong (South Korea) in 2018-2019, frozen, and preserved for 1-2 years. The preparation of the oyster hydrolysate $(\mathrm{OH})$ and YA was conducted according to a previous protocol [25]. The amino acid sequence of the purified peptide fragment in $\mathrm{OH}$ is determined using LC/MS/MS. The sequenced peptide YA was synthesized with a purity of $95 \%$ or higher to test their function. In addition, we validated histological changes in the liver and changes in liver enzymes (alanine aminotransferase, ALT; aspartate aminotransferase, AST) using synthetic YA purchased from Sigma-Aldrich (St. Louis, MI, USA).

\subsection{Measurement of Cyclooxygenase-2 (COX-2) and 5-Lipoxygenase (5-LO) Inhibition Activity}

The percentages of COX-2 inhibition and 5-LO inhibition of YA were measured according to the previous protocols [24]. Briefly, the assay mixture for COX-2 contained $450 \mu \mathrm{L}$ of Tris-HCl buffer (pH 8.0, $100 \mathrm{mM}), 100 \mu \mathrm{L}$ of hematin $(150 \mathrm{mM}), 100 \mu \mathrm{L}$ of ethylene-diaminetetraacetic acid (EDTA, $30 \mu \mathrm{M}), 200 \mu \mathrm{L}$ of COX-2 $(40 \mathrm{U} / \mathrm{mL})$, and $100 \mu \mathrm{L}$ of YA. The mixture was incubated for $15 \mathrm{~min}$ at room temperature. The reaction was initiated by adding $20 \mu \mathrm{L}$ of arachidonic acid $(20 \mathrm{mM})$ and $25 \mu \mathrm{L}$ of $\mathrm{N}, \mathrm{N}, \mathrm{N}^{\prime}, \mathrm{N}^{\prime}$-tetramethyl- $\rho$-phenylenediamine (TMPD, $10 \mathrm{mM}$ ) and evaluated after $5 \mathrm{~min}$ at $590 \mathrm{~nm}$. To measure 5-LO activity, $200 \mu \mathrm{L}$ of the enzyme solution $(160 \mathrm{U} / \mathrm{mL})$ were prepared in a $0.2 \mathrm{M}$ boric acid buffer $(\mathrm{pH} 9.0)$, mixed with $50 \mu \mathrm{L}$ of $Y A(1,3,5$, and $100 \mathrm{mg} / \mathrm{mL}$ in boric acid buffer), and then incubated at room temperature for $3 \mathrm{~min}$. The reaction was initiated by adding $250 \mu \mathrm{L}$ of the substrate solution (100 $\mu \mathrm{M}$ of linoleic acid) and evaluated for $2 \mathrm{~min}$ at $234 \mathrm{~nm}$ using the VERSAmax microplate reader (Molecular Devices, San Jose, CA, USA).

\subsection{LPS/D-GalN-Induced ALF Model}

The animal experiments were carried out in compliance with the animal care and use committee guidelines at Gyeongsang National University (GNU-151208-M0068). Male C57BL/ 6 mice (7 weeks old) were purchased from Koatech Co. (Animal Breeding Center, Pyongtaek, Korea). Animals were kept on a $12 \mathrm{~h}$ light/dark cycle in a specific pathogenfree area with food and water freely available in the animal facility for 1 week before the experiment. All experimental animals were randomly separated into five groups as follows: Saline, LPS $(1 \mu \mathrm{g} / \mathrm{kg})+$ D-GalN $(400 \mathrm{mg} / \mathrm{kg})$, LPS $/ D-G a l N+Y A(10 \mathrm{mg} / \mathrm{kg})$, LPS/DGalN + YA (50 mg/kg), and LPS/D-GalN + silymarin $(25 \mathrm{mg} / \mathrm{kg})$. YA and silymarin were pre-administered for 10 days before LPS/D-GalN by oral gavage. LPS/D-GalN was injected intraperitoneally. Blood and tissues were collected $6 \mathrm{~h}$ after LPS/D-GalN injection. Liver tissues were quickly isolated and placed into a deep freezer at $-80{ }^{\circ} \mathrm{C}$ or a $4 \%$ paraformaldehyde solution for further experimentation.

\subsection{Measurement of Alanine Aminotransferase (ALT) and Aspartate Aminotransferase (AST) Levels}

ALT and AST levels in the serum were measured by GC Labs (Yongin, Korea), which uses the International Federation of Clinical Chemistry standard method. ALT and AST levels were measured and analyzed according to previous methods [25]. 


\subsection{Hematoxylin and Eosin (HEE) Staining}

Histological changes in the liver tissue were analyzed by H\&E staining (Sigma Aldrich., St Louis, MO, USA). Mice were perfused with a fixative solution containing $4 \%$ paraformaldehyde solution, and the liver was isolated and incubated in the same fixative solution overnight at $4{ }^{\circ} \mathrm{C}$. The liver tissues were embedded in paraffin after washing three times. The paraffin blocks were sectioned to a thickness of $5 \mu \mathrm{m}$ and air-dried on gelatin-coated slides. For H\&E staining, the paraffin was removed from the liver tissue sections with xylene, and the tissue sections were rehydrated with graded alcohol series $(100 \%$ to $70 \% \mathrm{EtOH})$. The liver tissue section was washed with tap water for $5 \mathrm{~min}$, and the section slide was immersed in hematoxylin solution for $5 \mathrm{~min}$. After checking the degree of hematoxylin staining, eosin staining was performed for $1 \mathrm{~min}$. The sections were dehydrated through a graded series of $\mathrm{EtOH}$ ( $70 \%$ to $100 \% \mathrm{EtOH}$, each $3 \mathrm{~min})$, removed from xylene, and mounted with mounting medium (Fisher Chemical, Geel, Belgium). The stained part was photographed using a BX61VS microscope (Olympus, Tokyo, Japan).

\subsection{TUNEL Staining}

The apoptotic signal in the testes was assessed using the DeadEnd Fluorometric TUNEL System (Promega, Madison, WI, USA) according to the manufacturer's protocol. The TUNEL staining was carried out as described previously [56]. Deparaffinized liver tissue sections were fixed in $4 \%$ paraformaldehyde in PBS for $15 \mathrm{~min}$ at room temperature, washed three times in PBS, and permeabilized with $20 \mu \mathrm{g} / \mathrm{mL}$ proteinase $\mathrm{K}$ solution for $10 \mathrm{~min}$ at room temperature. After three washes in PBS, the slides were refixed in $4 \%$ paraformaldehyde for $5 \mathrm{~min}$ at room temperature. The slides were washed in PBS for $5 \mathrm{~min}$ and equilibrated in an equilibration buffer for $10 \mathrm{~min}$. The liver tissues on the slides were labeled with a TdT reaction mix for $60 \mathrm{~min}$ at $37^{\circ} \mathrm{C}$ in a dark, humidified chamber. The reaction was stopped with a $2 \times$ SSC solution, followed by washing three times in PBS. Counterstaining was carried out by incubating with $5 \mu \mathrm{g} / \mathrm{mL}$ PI for $10 \mathrm{~min}$ at room temperature in the dark. TUNEL-positive cells were observed using a confocal laser scanning microscope (Olympus).

\subsection{RT-PCR}

Total RNA isolated from liver tissues was used to synthesize first-strand cDNA using a reverse transcriptase kit (DiaStartTM RT kit; SolGent, Daejeon, Korea) for RT-PCR and real-time PCR. As previously mentioned, the procedure for RT-PCR was performed [57]. Table 1 shows the primer sequences used to detect mRNA of IL- $1 \beta$, IL-6, TNF- $\alpha$, and glyceraldehyde-3-phosphate dehydrogenase (GAPDH). GAPDH was used as a loading control. The PCR conditions included an initial denaturation at $94{ }^{\circ} \mathrm{C}$ for $5 \mathrm{~min}$, followed by 30 cycles of $94{ }^{\circ} \mathrm{C}$ for $30 \mathrm{~s}, 58{ }^{\circ} \mathrm{C}$ for $30 \mathrm{~s}$, and $72{ }^{\circ} \mathrm{C}$ for $30 \mathrm{~s}$, and a final extension step at $72{ }^{\circ} \mathrm{C}$ for $10 \mathrm{~min}$.

Table 1. Primer sequences used for PCR.

\begin{tabular}{|c|c|c|c|}
\hline $\begin{array}{l}\text { Gene } \\
\text { Name }\end{array}$ & $\begin{array}{l}\text { GenBank } \\
\text { Acc. No. }\end{array}$ & Primer Sequences $\left(5^{\prime}-3^{\prime}\right)$ & $\begin{array}{l}\text { Expected } \\
\text { Size (bp) }\end{array}$ \\
\hline$I L 1 b$ & NM_008361.4 & $\begin{array}{c}\text { Sense: GTTGACGGACCCCAAAAGAT } \\
\text { Antisense: TCGTTGCTTGGTTCTCCTTG }\end{array}$ & 440 \\
\hline IL6 & NM_031168 & $\begin{array}{l}\text { Sense: CTTCACAAGTCCGGAGAGGAG } \\
\text { Antisense: TGGTCTTGGTCCTTAGCCACT }\end{array}$ & 489 \\
\hline $\operatorname{Tnf}$ & D84199 & $\begin{array}{c}\text { Sense: CAGCCTCTTCTCATTCCTGCT } \\
\text { Antisense: TGTCCCTTGAAGAGAACCTGG }\end{array}$ & 339 \\
\hline GAPDH & NM_017008.4 & $\begin{array}{c}\text { Sense: CTA AAG GGC ATC CTG GGC } \\
\text { Antisense: TTA CTC CTT GGA GGC CAT }\end{array}$ & 201 \\
\hline
\end{tabular}




\subsection{Western Blot Analysis}

A Western blot analysis of total, cytoplasmic, and mitochondrial proteins was performed as described previously [25]. The total protein was isolated from liver tissue using the RIPA buffer ( $25 \mathrm{mM}$ Tris- $\mathrm{HCl}$ (pH 7.4), $150 \mathrm{mM} \mathrm{NaCl}, 1 \% \mathrm{NP}-40,1 \%$ deoxycholate, $0.1 \%$ sodium dodecyl sulfate (SDS); Thermo Fisher Scientific, Carlsbad, CA, USA) containing a $1 \times$ protease inhibitor cocktail (Roche Diagnostics, Indianapolis, IN, USA). According to the manufacturer's protocol, mitochondrial and cytosolic fractions were isolated using a mitochondria isolation kit for the tissue (Thermo Fisher Scientific). Equal amounts (30 $\mu \mathrm{g}$ ) of protein were analyzed among experimental groups. Equal volumes of the proteins and $2 \times$ SDS sample buffer were mixed, loaded on $10 \%$ SDS-polyacrylamide gel, and separated by electrophoresis for $120 \mathrm{~min}$ at $120 \mathrm{~V}$. Then, the gel was transferred to a polyvinylidene difluoride membrane (Millipore, Billerica, MA, USA) for $1 \mathrm{~h}$ at $100 \mathrm{~V}$ using a wet transfer system (Bio-Rad, Hercules, CA, USA). The membranes blocked with 5\% $(w / v)$ fat-free dry milk in TBS with tween-20 at room temperature for 60 min were incubated with anti-Bax (1:200 dilution; Santa Cruz Biotechnology, Dallas, TX, USA), anti-Bcl-2 (1:200 dilution; Santa Cruz Biotechnology), anti-cytochrome C (1:1000; Cell Signaling, Danvers, MA, USA), anti-VDAC (1:1000; Cell Signaling, Danvers, MA, USA), anti-caspase-3 (1:1000; Cell Signaling), anti-GRP78 (1:1000 dilution, Abcam., Cambridge, UK), anti-pERK (1:200 dilution; Santa Cruz Biotechnology), anti-p-pERK (1:200 dilution; Santa Cruz Biotechnology), anti-elF2 $\alpha$ (1:1000; Cell Signaling), anti-p-elF2 $\alpha$ (1:1000; Cell Signaling), anti-ATF4 (1:200 dilution; Santa Cruz Biotechnology), anti-ATF6 (1:1000; Cell Signaling), anti-CHOP (1:200 dilution; Santa Cruz Biotechnology), anti-HO-1 (1:200 dilution; Santa Cruz Biotechnology), anti-SLC7A11/xCT (1:1000, arigo Biolaboratories Corp., Hsinchu City, Taiwan), anti-GPx4 (1:1000, arigo Biolaboratories Corp), anti-4-HNE (1:1000, arigo Biolaboratories Corp), anti-caspase 1 (1:1000, Adipogen Corporation, San Diego, CA, USA), anti-GSDMD (1:1000, Abcam), anti-cleaved C-terminal GSDMD (1:1000, Abcam), and anti- $\beta$-actin antibody (1:5000 dilution; Thermo Fisher Scientific) at $4{ }^{\circ} \mathrm{C}$ overnight. After the primary antibody incubation, it was incubated with a secondary HRP-conjugated anti-rabbit or anti-mouse antibody at 1:10,000 (Assay Designs, Ann Arbor, MI, USA). Immuno-positive bands were enhanced with chemiluminescence (EzWestLumi plus; ATTO Gentaur, Tokyo, Japan) and visualized using the iBright CL1500 imaging system (Thermo Scientific Fisher/ Life Technologies Holdings Pte Ltd., Singapore).

\subsection{Measurement of IL-1 $\beta, I L-6$, and TNF- $\alpha$ Concentrations in Liver Tissues}

According to the manufacturer's protocol, the concentrations of the pro-inflammatory cytokines IL-1 $\beta$, IL-6, and TNF- $\alpha$ in the liver tissues were quantified using an ELISA kit (R\&D system, Minneapolis, MN, USA). The protocol was previously described [25]. The absorbance of the plates at $450 \mathrm{~nm}$ was read with a microplate reader (Molecular Devices).

\subsection{Measurement of Total and Phospho-NF-kB p65 Protein}

The semi-quantitative measurement of NF- $\mathrm{kB}$ p65 (pS536) and total NF- $\mathrm{kB}$ p65 protein was performed using an ELISA kit (NF-kB p65 (pS536 + Total), Abcam) according to the manufacturer's protocol. The $100 \mathrm{mg}$ of liver tissues were homogenized in cold $1 \times$ Extraction Buffer PTR (Abcam). The homogenates were incubated in ice for $20 \mathrm{~min}$ and subjected to centrifugation at $18,000 \times g$ for $20 \mathrm{~min}$ at $4{ }^{\circ} \mathrm{C}$ (Eppendorf Centrifuge $5424 \mathrm{R}$, Eppendorf AG). After centrifugation, the supernatant was transferred to a clean tube and provided as tissue lysates. The protein concentration of tissue lysate was quantified using the BCA assay kit. Then, the tissue lysates were diluted to the desired concentration using $1 \times$ Extraction Buffer PTR. The diluted tissue lysates $(50 \mu \mathrm{L})$, antibody cocktail (the mixture

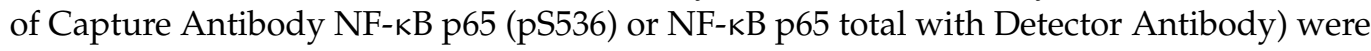
added to a 96-well plate. The plates were covered with an adhesive strip, incubated for $1 \mathrm{~h}$ at room temperature, and washed three times with $1 \times$ wash buffer PT. Then, $100 \mu \mathrm{L}$ of TMB substrate were added and incubated at room temperature for $15 \mathrm{~min}$ in the dark on a plate shaker set to $400 \mathrm{rpm}$. The reaction was quenched by adding $100 \mu \mathrm{L}$ stop solution, 
and the absorbance of the plates was read at $450 \mathrm{~nm}$ with a microplate reader (Molecular Devices, Sunnyvale, CA, USA).

\subsection{Data Analysis and Statistics}

The images of the Western blots and agarose gel were captured using an iBright CL1500 imaging system (Thermo Scientific Fisher/Life Technologies Holdings Pte Ltd.). The bands were quantified by ImageJ software (version 1.49, National Institutes of Health, Bethesda, MD, USA). Data are presented as the mean \pm standard deviation (SD). The one-way ANOVA/Bonferroni test or the Kruskal-Wallis/Mann-Whitney test was selected after the normality test to analyze differences among groups (OriginPro2020, OriginLab Corp., Northampton, MA, USA). A $p<0.05$ value was considered as the statistical significance criterion.

\section{Conclusions}

Our findings demonstrate that YA regulates a complex mechanism induced by LPS/DGalN. YA has anti-inflammatory, anti-apoptotic, anti-pyroptotic, and anti-ferroptotic effects against LPS/D-GalN-induced hepatic inflammation and cell death. YA may be a potential marine anti-inflammatory and antioxidative agent for treating acute liver diseases such as ALF.

Author Contributions: Conceptualization, S.S.K., Y.J.C. and D.K.; Data curation, A.S.S., M.M.N. and D.K.; Formal analysis, A.S.S., M.M.N., E.-J.K. and D.K.; Funding acquisition, S.S.K., Y.J.C., D.R.K. and D.K.; Investigation, A.S.S., M.M.N., E.-J.K., M.S.W. and D.K.; Methodology, A.S.S., M.M.N.; Project administration, E.-J.K.; Resources, Y.J.C.; Supervision, S.-G.H., J.H.; Writing—original draft, A.S.S., S.B.C. and D.K.; Writing - review and editing, D.K.L., J.H., S.S.K., S.-G.H. and D.K. All authors have read and agreed to the published version of the manuscript.

Funding: This work was supported by the National Research Foundation of Korea (MSIT, NRF2015R1A-5A-2008833 and 2021R1I1A3044128) and by the Ministry of Oceans and Fisheries (Korea, D11410119H480000110/\#2014042).

Institutional Review Board Statement: The study was conducted according to the guidelines of the Declaration of Helsinki and approved by the animal care and use committee of Gyeongsang National University (GNU-151208-M0068).

Data Availability Statement: The study did not report any data.

Acknowledgments: This work was from Adrian Syawaluddin Siregar's thesis for the degree of Doctor of Philosophy ("Hepatoprotective effect of dipeptide tyrosine-alanine in ethanol and lipopolysaccharide-induced liver injury models", 2021, Department of Convergence Medical Science, Graduate School, Gyeongsang National University).

Conflicts of Interest: The authors declare no conflict of interest. The funding sponsors had no role in the design of the study; in the collection, analyses, or interpretation of the data; in the writing of the manuscript; or in the decision to publish the results.

\section{References}

1. Bernal, W.; Wendon, J. Acute liver failure. N. Engl. J. Med. 2013, 369, 2525-2534. [CrossRef] [PubMed]

2. Toma, D.; Lazar, O.; Bontas, E. Acute Liver Failure; Springer Nature Switzerland AG: Cham, Switzerland, 2020 ; p. 12.

3. Rolando, N.; Wade, J.; Davalos, M.; Wendon, J.; Philpott-Howard, J.; Williams, R. The systemic inflammatory response syndrome in acute liver failure. Hepatology 2000, 32, 734-739. [CrossRef]

4. Rolando, N.; Harvey, F.; Brahm, J.; Philpott-Howard, J.; Alexander, G.; Gimson, A.; Casewell, M.; Fagan, E.; Williams, R. Prospective study of bacterial infection in acute liver failure: An analysis of fifty patients. Hepatology 1990, 11, 49-53. [CrossRef]

5. Zhai, X.R.; Tong, J.J.; Wang, H.M.; Xu, X.; Mu, X.Y.; Chen, J.; Liu, Z.F.; Wang, Y.; Su, H.B.; Hu, J.H. Infection deteriorating hepatitis $B$ virus related acute-on-chronic liver failure: A retrospective cohort study. BMC Gastroenterol. 2020, 20, 320. [CrossRef]

6. Yin, X.; Gong, X.; Zhang, L.; Jiang, R.; Kuang, G.; Wang, B.; Chen, X.; Wan, J. Glycyrrhetinic acid attenuates lipopolysaccharideinduced fulminant hepatic failure in D-galactosamine-sensitized mice by up-regulating expression of interleukin-1 receptorassociated kinase-M. Toxicol. Appl. Pharmacol. 2017, 320, 8-16. [CrossRef] 
7. Seo, M.J.; Hong, J.M.; Kim, S.J.; Lee, S.M. Genipin protects D-galactosamine and lipopolysaccharide-induced hepatic injury through suppression of the necroptosis-mediated inflammasome signaling. Eur. J. Pharmacol. 2017, 812, 128-137. [CrossRef] [PubMed]

8. Kemelo, M.K.; Wojnarova, L.; Kutinova Canova, N.; Farghali, H. D-galactosamine/lipopolysaccharide-induced hepatotoxicity downregulates sirtuin 1 in rat liver: Role of sirtuin 1 modulation in hepatoprotection. Physiol. Res. 2014, 63, 615-623. [CrossRef]

9. Nowak, M.; Gaines, G.C.; Rosenberg, J.; Minter, R.; Bahjat, F.R.; Rectenwald, J.; MacKay, S.L.; Edwards, C.K., 3rd; Moldawer, L.L. LPS-induced liver injury in D-galactosamine-sensitized mice requires secreted TNF-alpha and the TNF-p55 receptor. Am. J. Physiol. Regul. Integr. Comp. Physiol. 2000, 278, R1202-R1209. [CrossRef] [PubMed]

10. Guha, M.; Mackman, N. LPS induction of gene expression in human monocytes. Cell. Signal. 2001, 13, 85-94. [CrossRef]

11. Martich, G.D.; Danner, R.L.; Ceska, M.; Suffredini, A.F. Detection of interleukin 8 and tumor necrosis factor in normal humans after intravenous endotoxin: The effect of antiinflammatory agents. J. Exp. Med. 1991, 173, 1021-1024. [CrossRef]

12. Wang, H.; Xu, D.-X.; Lv, J.-W.; Ning, H.; Wei, W. Melatonin attenuates lipopolysaccharide (LPS)-induced apoptotic liver damage in D-galactosamine-sensitized mice. Toxicology 2007, 237, 49-57. [CrossRef] [PubMed]

13. Newsome, P.N.; Plevris, J.N.; Nelson, L.J.; Hayes, P.C. Animal models of fulminant hepatic failure: A critical evaluation. Liver Transplant. 2000, 6, 21-31. [CrossRef]

14. Eipel, C.; Kidess, E.; Abshagen, K.; Leminh, K.; Menger, M.D.; Burkhardt, H.; Vollmar, B. Antileukoproteinase protects against hepatic inflammation, but not apoptosis in the response of D-galactosamine-sensitized mice to lipopolysaccharide. Br. J. Pharmacol. 2007, 151, 406-413. [CrossRef]

15. Li, J.; Zhong, L.; Zhu, H.; Wang, F. The Protective Effect of Cordycepin on D-Galactosamine/Lipopolysaccharide-Induced Acute Liver Injury. Mediat. Inflamm. 2017, 2017, 3946706. [CrossRef]

16. Li, L.; Yin, H.; Zhao, Y.; Zhang, X.; Duan, C.; Liu, J.; Huang, C.; Liu, S.; Yang, S.; Li, X. Protective role of puerarin on LPS/D-Gal induced acute liver injury via restoring autophagy. Am. J. Transl. Res. 2018, 10, 957-965.

17. Li, H.; Zhao, X.K.; Cheng, Y.J.; Zhang, Q.; Wu, J.; Lu, S.; Zhang, W.; Liu, Y.; Zhou, M.Y.; Wang, Y.; et al. Gasdermin D-mediated hepatocyte pyroptosis expands inflammatory responses that aggravate acute liver failure by upregulating monocyte chemotactic protein 1/CC chemokine receptor-2 to recruit macrophages. World J. Gastroenterol. 2019, 25, 6527-6540. [CrossRef] [PubMed]

18. Bai, L.; Kong, M.; Duan, Z.; Liu, S.; Zheng, S.; Chen, Y. M2-like macrophages exert hepatoprotection in acute-on-chronic liver failure through inhibiting necroptosis-S100A9-necroinflammation axis. Cell Death Dis. 2021, 12, 93. [CrossRef]

19. Wang, Y.; Chen, Q.; Shi, C.; Jiao, F.; Gong, Z. Mechanism of glycyrrhizin on ferroptosis during acute liver failure by inhibiting oxidative stress. Mol. Med. Rep. 2019, 20, 4081-4090. [CrossRef]

20. Padmanabhan, P.; Jangle, S. Hepatoprotective activity of herbal preparation (HP-4) against alcohol induced hepatotoxicity in mice. Int. J. Appl. Sci. Biotechnol. 2014, 2, 50-58. [CrossRef]

21. Yang, S.; Kuang, G.; Zhang, L.; Wu, S.; Zhao, Z.; Wang, B.; Yin, X.; Gong, X.; Wan, J. Mangiferin Attenuates LPS/D-GalN-Induced Acute Liver Injury by Promoting HO-1 in Kupffer Cells. Front. Immunol. 2020, 11, 285. [CrossRef] [PubMed]

22. Gillessen, A.; Schmidt, H.H. Silymarin as Supportive Treatment in Liver Diseases: A Narrative Review. Adv. Ther. 2020, 37, 1279-1301. [CrossRef]

23. Doehmer, J.; Tewes, B.; Klein, K.U.; Gritzko, K.; Muschick, H.; Mengs, U. Assessment of drug-drug interaction for silymarin. Toxicol. Vitr. Int. J. Publ. Assoc. BIBRA 2008, 22, 610-617. [CrossRef]

24. Ryu, J.H.; Kim, E.J.; Xie, C.; Nyiramana, M.M.; Siregar, A.S.; Park, S.H.; Cho, S.B.; Song, D.H.; Kim, N.G.; Choi, Y.J.; et al. Hepatoprotective Effects of Oyster Hydrolysate on Lipopolysaccharide/D-galactosamine-Induced Acute Liver Injury in Mice. J. Korean Soc. Food Sci. Nutr. 2017, 46, 659-670.

25. Siregar, A.S.; Nyiramana, M.M.; Kim, E.J.; Shin, E.J.; Woo, M.S.; Kim, J.M.; Kim, J.H.; Lee, D.K.; Hahm, J.R.; Kim, H.J.; et al Dipeptide YA is Responsible for the Positive Effect of Oyster Hydrolysates on Alcohol Metabolism in Single Ethanol Binge Rodent Models. Mar. Drugs 2020, 18, 512. [CrossRef] [PubMed]

26. Baig, M.H.; Ahmad, K.; Saeed, M.; Alharbi, A.M.; Barreto, G.E.; Ashraf, G.M.; Choi, I. Peptide based therapeutics and their use for the treatment of neurodegenerative and other diseases. Biomed. Pharm. 2018, 103, 574-581. [CrossRef] [PubMed]

27. Moon, C.; Han, J.R.; Park, H.J.; Hah, J.S.; Kang, J.L. Synthetic RGDS peptide attenuates lipopolysaccharide-induced pulmonary inflammation by inhibiting integrin signaled MAP kinase pathways. Respir. Res. 2009, 10, 18. [CrossRef]

28. Schon, H.T.; Bartneck, M.; Borkham-Kamphorst, E.; Nattermann, J.; Lammers, T.; Tacke, F.; Weiskirchen, R. Pharmacological Intervention in Hepatic Stellate Cell Activation and Hepatic Fibrosis. Front. Pharmacol. 2016, 7, 33. [CrossRef]

29. Yu, H.; Lin, L.; Zhang, Z.; Zhang, H.; Hu, H. Targeting NF-kappaB pathway for the therapy of diseases: Mechanism and clinical study. Signal Transduct. Target. Ther. 2020, 5, 209. [CrossRef]

30. Xiao, K.; Liu, C.; Tu, Z.; Xu, Q.; Chen, S.; Zhang, Y.; Wang, X.; Zhang, J.; Hu, C.A.; Liu, Y. Activation of the NF-kappaB and MAPK Signaling Pathways Contributes to the Inflammatory Responses, but Not Cell Injury, in IPEC-1 Cells Challenged with Hydrogen Peroxide. Oxid. Med. Cell. Longev. 2020, 2020, 5803639. [CrossRef]

31. Liu, T.; Zhang, L.; Joo, D.; Sun, S.C. NF-kappaB signaling in inflammation. Signal Transduct. Target. Ther. 2017, 2, 1-9. [CrossRef]

32. Wu, Y.H.; Hu, S.Q.; Liu, J.; Cao, H.C.; Xu, W.; Li, Y.J.; Li, L.J. Nature and mechanisms of hepatocyte apoptosis induced by D-galactosamine/lipopolysaccharide challenge in mice. Int. J. Mol. Med. 2014, 33, 1498-1506. [CrossRef]

33. Li, M.; Song, K.; Huang, X.; Fu, S.; Zeng, Q. GDF-15 prevents LPS and D-galactosamine-induced inflammation and acute liver injury in mice. Int. J. Mol. Med. 2018, 42, 1756-1764. [CrossRef] 
34. Ren, F.; Yang, B.; Zhang, X.; Wen, T.; Wang, X.; Yin, J.; Piao, Z.; Zheng, S.; Zhang, J.; Chen, Y.; et al. Role of endoplasmic reticulum stress in D-GalN/LPS-induced acute liver failure. Zhonghua Gan Zang Bing Za Zhi Chin. J. Hepatol. Abs 2014, 22, 364-368. [CrossRef]

35. Wang, H.; Chen, L.; Zhang, X.; Xu, L.; Xie, B.; Shi, H.; Duan, Z.; Zhang, H.; Ren, F. Kaempferol protects mice from D-GalN/LPSinduced acute liver failure by regulating the ER stress-Grp78-CHOP signaling pathway. Biomed. Pharmacother. 2019, 111, 468-475. [CrossRef]

36. Chen, L.; Ren, F.; Zhang, H.; Wen, T.; Piao, Z.; Zhou, L.; Zheng, S.; Zhang, J.; Chen, Y.; Han, Y.; et al. Inhibition of glycogen synthase kinase 3 beta ameliorates D-GalN/LPS-induced liver injury by reducing endoplasmic reticulum stress-triggered apoptosis. PLoS ONE 2012, 7, 45202. [CrossRef]

37. Zhang, K.; Kaufman, R.J. From endoplasmic-reticulum stress to the inflammatory response. Nature 2008, 454, 455-462. [CrossRef] [PubMed]

38. Lebeaupin, C.; Proics, E.; de Bieville, C.H.; Rousseau, D.; Bonnafous, S.; Patouraux, S.; Adam, G.; Lavallard, V.J.; Rovere, C.; Le Thuc, O.; et al. ER stress induces NLRP3 inflammasome activation and hepatocyte death. Cell Death Dis. 2015, 6, 1879. [CrossRef]

39. Lee, Y.S.; Lee, D.H.; Choudry, H.A.; Bartlett, D.L.; Lee, Y.J. Ferroptosis-Induced Endoplasmic Reticulum Stress: Cross-Talk between Ferroptosis and Apoptosis. Mol. Cancer Res. MCR 2018, 16, 1073-1076. [CrossRef]

40. Mao, L.; Zhao, T.; Song, Y.; Lin, L.; Fan, X.; Cui, B.; Feng, H.; Wang, X.; Yu, Q.; Zhang, J.; et al. The emerging role of ferroptosis in non-cancer liver diseases: Hype or increasing hope? Cell Death Dis. 2020, 11, 518. [CrossRef] [PubMed]

41. Xie, Y.; Hou, W.; Song, X.; Yu, Y.; Huang, J.; Sun, X.; Kang, R.; Tang, D. Ferroptosis: Process and function. Cell Death Differ. 2016, 23, 369-379. [CrossRef]

42. Ji, Y.; Si, W.; Zeng, J.; Huang, L.; Huang, Z.; Zhao, L.; Liu, J.; Zhu, M.; Kuang, W. Niujiaodihuang Detoxify Decoction Inhibits Ferroptosis by Enhancing Glutathione Synthesis in Acute Liver Failure Models. J. Ethnopharmacol. 2021, 279, 114305. [CrossRef] [PubMed]

43. Demarco, B.; Chen, K.W.; Broz, P. Cross talk between intracellular pathogens and cell death. Immunol. Rev. 2020, $297,174-193$. [CrossRef] [PubMed]

44. Chakrabarti, S.; Jahandideh, F.; Wu, J. Food-derived bioactive peptides on inflammation and oxidative stress. BioMed. Res. Int. 2014, 2014, 608979. [CrossRef]

45. Xie, C.L.; Kang, S.S.; Lu, C.; Choi, Y.J. Quantification of Multifunctional Dipeptide YA from Oyster Hydrolysate for Quality Control and Efficacy Evaluation. BioMed. Res. Int. 2018, 2018, 8437379. [CrossRef]

46. Xie, C.L.; Kim, J.S.; Ha, J.M.; Choung, S.Y.; Choi, Y.J. Angiotensin I-converting enzyme inhibitor derived from cross-linked oyster protein. BioMed. Res. Int. 2014, 2014, 379234. [CrossRef]

47. Byun, J.-H.; Shin, J.E.; Choi, Y.-J.; Choung, S.-Y. Oyster hydrolysate ameliorates ethanol diet-induced alcoholic fatty liver by regulating lipid metabolism in rats. Int. J. Food Sci. Technol. 2021, 56, 11. [CrossRef]

48. Felig, P. The glucose-alanine cycle. Metab. Clin. Exp. 1973, 22, 179-207. [CrossRef]

49. Okun, J.G.; Rusu, P.M.; Chan, A.Y.; Wu, Y.; Yap, Y.W.; Sharkie, T.; Schumacher, J.; Schmidt, K.V.; Roberts-Thomson, K.M.; Russell, R.D.; et al. Liver alanine catabolism promotes skeletal muscle atrophy and hyperglycaemia in type 2 diabetes. Nat. Metab. 2021, 3, 394-409. [CrossRef]

50. McCommis, K.S.; Chen, Z.; Fu, X.; McDonald, W.G.; Colca, J.R.; Kletzien, R.F.; Burgess, S.C.; Finck, B.N. Loss of Mitochondrial Pyruvate Carrier 2 in the Liver Leads to Defects in Gluconeogenesis and Compensation via Pyruvate-Alanine Cycling. Cell Metab. 2015, 22, 682-694. [CrossRef]

51. Kim, W.R.; Flamm, S.L.; di Bisceglie, A.M.; Bodenheimer, H.C.; Public Policy Committee of the American Association for the Study of Liver, D. Serum Activity of Alanine Aminotransferase (ALT) as an Indicator of Health and Disease. Hepatology 2008, 47, 1363-1370. [CrossRef]

52. Maezono, K.; Mawatari, K.; Kajiwara, K.; Shinkai, A.; Maki, T. Effect of alanine on D-galactosamine-induced acute liver failure in rats. Hepatology 1996, 24, 1211-1216. [CrossRef]

53. Maezono, K.; Kajiwara, K.; Mawatari, K.; Shinkai, A.; Torii, K.; Maki, T. Alanine protects liver from injury caused by Fgalactosamine and CCl4. Hepatology 1996, 24, 185-191. [CrossRef] [PubMed]

54. Litwack, G. Metabolism of Amino Acids. In Human Biochemistry; Academic Press: Cambridge, MA, USA, 2018. [CrossRef]

55. Levine, R.J.; Conn, H.O. Tyrosine metabolism in patients with liver disease. J. Clin. Investig. 1967, 46, 2012-2020. [CrossRef]

56. Siregar, A.S.; Nyiramana, M.M.; Kim, E.-J.; Shin, E.-J.; Kim, C.-W.; Lee, D.; Hong, S.-G.; Han, J.; Kang, D. TRPV1 Is Associated with Testicular Apoptosis in Mice. J. Anim. Reprod. Biotechnol. 2019, 34, 7. [CrossRef]

57. Yang, J.H.; Siregar, A.S.; Kim, E.J.; Nyiramana, M.M.; Shin, E.J.; Han, J.; Sohn, J.T.; Kim, J.W.; Kang, D. Involvement of TREK-1 Channel in Cell Viability of H9c2 Rat Cardiomyoblasts Affected by Bupivacaine and Lipid Emulsion. Cells 2019, 8, 454. [CrossRef] [PubMed] 